\title{
Prospecção Tecnológica de Patentes a Respeito da Produção de Diesel Verde a partir de Microalgas com Catalisadores de Nióbio por Pirólise Rápida
}

\author{
Prospective Study of Patents About the Production of Green Diesel from \\ Microalgae With Niobium Catalysts by fast Pyrolysis
}

\author{
Mailena Silva Dourado ${ }^{1}$ \\ Beatrice Araújo Mascarenhas ${ }^{1}$ \\ Odete Gonçalves ${ }^{1}$ \\ Roger Thomas Fréty ${ }^{1}$ \\ Emerson Andrade Sales ${ }^{1}$ \\ ${ }^{1}$ Universidade Federal da Bahia, Salvador, BA, Brasil
}

\begin{abstract}
Resumo
Nos dias de hoje, as microalgas vêm sendo investigadas como fonte de matéria-prima para produzir biocombustíveis devido à sua alta produtividade, ao elevado teor lipídico e à capacidade de crescer em uma grande variedade de climas e de espaços, sem competir com a produção de alimentos. Este trabalho tem como finalidade identificar as patentes referentes à produção de diesel verde a partir de microalgas, empregando catalisadores de nióbio no processo de pirólise. Para isso, foi realizada uma pesquisa nos bancos de dados Espacenet e Instituto Nacional da Propriedade Industrial (INPI), por meio de códigos indexados na Classificação Internacional de Patentes (CIP). Os resultados mostram que não foram encontradas tecnologias usando pirólise rápida e catalisadores de nióbio para transformar os lipídios de microalgas em combustíveis verdes, o que pode justificar a necessidade de um estudo na área.
\end{abstract}

Palavras-chave: Microalgas. Diesel verde. Catalisador de Nióbio.

\begin{abstract}
In recent periods microalgae have been investigated as a source of raw material to produce biofuels, due to their high productivity, high lipid content and ability to grow in a wide variety of climates and spaces without competing with food production. This work aims to identify the patents related to the production of green diesel from microalgae using pyrolysis processes and niobium-based catalysts. For this, a search was conducted in the database - Espacenet followed by the National Institute of Industrial Property (INPI), for codes indexed in the International Patent Classification (CIP). The results show that technologies using rapid pyrolysis and niobium catalysts to transform lipids from microalgae into green fuels are non-existent, which may justify a study in the area.
\end{abstract}

Keywords: Microalgae. Green diesel. Niobium-based Catalyst.

Áreas Tecnológicas: Biocombustíveis. Química Verde. Prospecção Tecnológica. 


\section{Introdução}

De acordo com Mercer e Armenta (2011), as microalgas são organismos pertencentes ao reino protista que compreendem um grupo muito diverso de organismos fotossintetizantes. São microscópicos, unicelulares ou pluricelulares, presentes tanto no meio aquático doce ou salino como no solo (bentônicas).

Santos et al. (2018) realizaram um estudo de patentes sobre o cultivo de microalgas visando à produção de biodiesel e verificaram que tecnologias com a finalidade de transformar biomassa de microalgas em biocombustíveis está em crescimento. Pimentel, Aquino e Lobato (2018) avaliaram o uso da biomassa úmida de microalgas para a produção de biodiesel e destacaram que essa tecnologia é promissora, uma vez que a etapa de secagem (a que possui maior gasto energético) não se faz necessária. Dessa forma, os processos para a transformação da biomassa e/ou fração lipídica em combustíveis renováveis apresentam um elevado potencial para substituir parcialmente a demanda energética.

Tecnologias com a finalidade de transformar biomassa de microalgas em biocombustíveis estão em crescimento (DOS SANTOS, 2018). Esses autores realizaram um estudo de patentes de cultivo de microalgas visando à produção de biodiesel (DOS SANTOS, 2018), enquanto Pimentel, Aquino e Lobato (2018) avaliaram o uso da biomassa úmida de microalgas para a produção de biodiesel. Dessa forma, os processos de tecnologia para a transformação da biomassa e/ou fração lipídica em combustíveis renováveis apresentam um elevado potencial para substituir parcialmente a demanda energética.Os processos de conversão de microalgas em biocombustíveis podem ser classificados em bioquímicos, químicos e termoquímicos. O processo bioquímico mais conhecido é a fermentação que produz bioálcool, e o processo químico mais usado é a transesterificação para a produção de biodiesel. Os processos termoquímicos incluem os diversos tipos de pirólises, a liquefação e o hidrotratamento (SUALI; SARBATLY, 2012).

A pirólise é um processo de conversão termoquímica que ocorre na ausência de oxigênio, convertendo material orgânico lignocelulósico ou da biomassa de microalgas, em produtos sólidos, líquidos e gasosos (BRIDGWATER, 2012). A pirólise de microalgas gera bio-óleo contendo hidrocarbonetos, produtos mono ou polioxigenados, nitrogenados, entre outros. Quando realizada na presença de um catalisador, a pirólise conduz a produtos fortemente desoxigenados, promissores como precursores de biocombustíveis e/ou de "drop in fuels" (CHAGAS et al., 2016).

A pirólise rápida da microalga Chlorella foi estudada nas temperaturas de 300, 350, 400 e $450^{\circ} \mathrm{C}$ (BABICH et al., 2011). Na presença do catalisador carbonato de sódio (NaCO), o bio-óleo obtido apresentou baixo conteúdo de ácidos, elevado volume de aromáticos e mostrou, em maior temperatura, grande rendimento em produtos líquidos, evidenciando um excelente potencial para produção de biocombustível de alta qualidade. Du et al. (2011) estudaram a pirólise da biomassa Chlorella sp em um forno de micro-ondas e verificaram que o bio-óleo obtido era composto, principalmente, de hidrocarbonetos alifáticos e aromáticos, fenóis, ácidos graxos de cadeia longa e nitrogenados. Zainan et al. (2018) investigaram a produção e a qualidade do bio-óleo produzido a partir de pirólise catalítica e não catalítica da microalga Chlorella vulgaris, e os resultados mostraram que a pirólise catalítica usando zeólita ZSM-5 como suporte de Níquel (Ni) produziu uma fase líquida com maior teor de hidrocarbonetos e menor teor em 
compostos oxigenados e/ou ácidos que a pirólise não catalítica. A Spirulina maxima, cianobactéria geralmente considerada como microalga, foi pirolisada em presença de óxido de nióbio hidratado, os produtos resultantes dessa pirólise foram comparados aos obtidos com os resultados da pirólise utilizando o catalisador HZSM-5: niobia e verificou-se que o primeiro foi menos eficiente em desoxigenação e em conversão do que a zeolita (SIMÃO et al., 2018). Elkasabi et al. (2016) desenvolveram um processo para aperfeiçoar o bio-óleo da cianobactéria Spirulina, usando uma combinação de hidrotratamento catalítico e purificação do bio-óleo. No bio-óleo, foi obtido alto rendimento de produtos desoxigenados e grande quantidade de hidrocarbonetos. A pirólise com as microalgas Chlorella vulgaris e Arthrospira platensis confirmaram seu grande potencial na produção de compostos aromáticos importantes como: tolueno, estireno e fenóis (ALMEIDA et al., 2017).

O Brasil é o maior produtor e exportador de nióbio no mundo, tendo mais de $90 \%$ das reservas mundiais exploráveis. O Ministério de Minas e Energiado Brasil recomenda ampliar e disseminar a utilização de nióbio no país pelas indústrias siderúrgicas e metalúrgicas, além de fomentar, por meio de pesquisa, o desenvolvimento de novos produtos e compostos para uso em setores de tecnologias avançadas como metais especiais, equipamentos médicos e óticos, indústria aeronáutica, aeroespacial e automobilística (BRASIL, 2020a). A partir da década de 1980, os materiais contendo nióbio ganharam espaço nas pesquisas ligadas à catálise (LOPES et al., 2015). O uso de catalisadores na pirólise aumenta o rendimento de produtos desoxigenados quando comparado com a pirólise sem catalisador. Os óxidos de nióbio, quando adicionados a outros catalisadores, aumentam acentuadamente a atividade e a seletividade catalítica $e$ prolongam a vida do catalisador, podendo ser usados em várias reações (TANABE, 2003). O óxido de nióbio é utilizado para várias reações, como hidratação, desidratação, esterificação, condensação, entre outros (REGUERA et al., 2004). No entanto, existem poucos relatos na literatura a respeito do uso de catalisadores à base de nióbio no processo de pirólise para a produção de biocombustíveis (BATISTA et al., 2019; SIMÃO et al., 2018).

Estudo sobre a transformação de compostos oleosos na presença de catalisadores à base de nióbio aparece escasso na literatura (BRANDÃO et al., 2009). Esses pesquisadores pirolisaram óleo de soja nas temperaturas entre 350 e $400^{\circ} \mathrm{C}$, usando nióbio modificado ou não, com ácidos minerais. A acidez da fase orgânica recuperada no final da reação em presença de catalisadores de nióbio sempre foi superior à acidez da fase líquida obtida após pirólise sem catalisador, sugerindo que os catalisadores de nióbio puro e modificados estavam estabilizando os ácidos graxos, primeiros intermediários, durante craqueio de trigliceridos; portanto, eram de interesse limitado para desoxigenação e obtenção de hidrocarbonetos. Reguera et al. (2004) usaram diferentes catalisadores à base de nióbio para quebrar o ácido oleico, $\mathrm{C} 18: 1$, a $400^{\circ} \mathrm{C}$. $\mathrm{O}$ fosfato de nióbio ( $\mathrm{NbOPO}$ ) e, principalmente, o pentóxido de nióbio $(\mathrm{NbO})$ impregnado com ácido fosfórico, em menor grau, geraram não só rendimentos satisfatórios em produtos desoxigenados na "fração diesel", mas também altos rendimentos em espécies "lubrificantes", isto é, em moléculas de longas cadeias do carbono. Esses resultados obtidos são provavelmente devidos às temperaturas baixas de pirólise usadas nesses estudos. Yi et al. (2015) estudaram o processo de hidrodeoxigenação com os catalisadores $\mathrm{Pd} / \mathrm{Nb}-\mathrm{SiO}$, e o estudo mostrou que a presença de $\mathrm{Nb}$ praticamente elimina a quebra das ligaçoes $\mathrm{C}-\mathrm{C}$ durante a transformação do ácido palmítico 
(C16: 0) e outros compostos oleosos. Xia et al. (2016) utilizaram catalisadores suportados Pd/ $\mathrm{NbOPO}$ e obtiveram um rendimento em alcanos na faixa diesel durante a transformação de triglicerídeos sob pressão de hidrogênio e temperatura moderada, sem ou com desativação limitada do catalisador. Um efeito sinérgico entre o paládio (Pd metálico) e a acidez de Lewis do $\mathrm{NbOPO}$ foi proposto para explicar os resultados. Assim, conforme exibido, alguns resultados da literatura mostram que catalisadores baseados em nióbio apresentam propriedades desejáveis e corroboram a necessidade de novos estudos na área.

Entretanto, antes de iniciar tecnicamente um novo trabalho de pesquisa contemplando lipídios de microalgas, pirólise rápida e catalisadores a base de nióbio, foi verificada a situação das patentes sobre parte desse assunto. Essa revisão de patentes foi o objeto principal do presente trabalho.

\section{Metodologia}

A prospecção tecnológica aqui apresentada é resultado de um estudo abrangente nos bancos de dados de patentes nacionais - Instituto Nacional da Propriedade Industrial (INPI) $-e$ internacionais - Espacenet, utilizando os códigos da Classificação Internacional de Patentes (CIP). A busca ocorreu no mês de janeiro do ano de 2020. Para a análise quantitativa e estatística dos documentos recuperados na busca e a sua respectiva análise de impacto, foi utilizada a ferramenta do Excel e o Google sheets para a construção das tabelas e dos gráficos apresentados.

Foram empregadas as palavras-chave: "microalgae", "biofuels", "pyrolysis", "pyrolytic", "green diesel", "catalysis", "catalytic", "niobium", Nannochloropsis e Chlorella. Não foi encontrado nenhum registro de patentes utilizando a espécie da microalga Halamphora.

A pesquisa foi do tipo avançada de modo a permitir o uso de operadores booleanos, a formação e a combinação de resultados de pesquisa, além de não estipular tempo.

A estratégia de busca consistiu no estudo inicial de patentes contendo combinações das palavras-chave descritas anteriormente. Nesse momento, foram selecionados arranjos que resultassem em quantidades inferiores a 100 patentes, de modo a possibilitar a leitura dos resumos. Posteriormente, forami realizadas uma triagem dos resumos que se assemelhassem ao tema do estudo e, então, uma análise dos códigos utilizados nessas patentes.

A seguinte expressão de busca foi utilizada: "microalga*" and "pyroly*", resultando em 36 patentes, e "cataly*" and "chlorella", resultando em 17 patentes. Após a leitura e filtragem dos resumos que se assemelhassem ao tema do estudo, foi realizada uma análise dos códigos utilizados nestas.

A partir da análise, foram eleitos códigos que representassem o tema proposto para o estudo, o qual envolve a produção de biocombustíveis a partir de processos, como a pirólise. Dessa forma, a estratégia final de busca abarcou os códigos e suas combinações, a exemplo, C11B1/10 e C12P7/64. Assim, um total de 326 patentes foi localizado, e, no final, 312 foram pertinentes para este estudo. As principais patentes referem-se a métodos de extração e de tratamento de extratos lipídicos usando leveduras e fungos (ALEXANDER et al., 1973; FORT JEAN, 1976).

A Tabela 1 apresenta a descrição dos códigos utilizados na pesquisa. 
Tabela 1 - Descrição dos códigos utilizados

\begin{tabular}{ccc} 
N. & CóDigo & Descrição \\
1 & C11B1/10 & Produção de gordura e ácidos graxos a partir de material vegetal. \\
2 & C12P7/64 & Produção de compostos orgânicos contendo oxigênio. \\
3 & F23G5/027 & Destilação, gaseificação e pirólise de biomassas. \\
4 & C10L1/02 & Produção de biocombustíveis líquidos. \\
\hline
\end{tabular}

Fonte: Elaborada pelos autores deste artigo (2020)

A investigação aqui descrita obteve como resultado uma abrangência significativa, mas que não representa sua totalidade, visto que a mesma patente pode vir a ser depositada em países diferentes (PCT), havendo, assim, um recobrimento. Ainda assim, foram analisados cerca de $95 \%$ dos documentos.

A Tabela 2 apresenta o escopo da estratégia adotada na busca.

Tabela 2 - Escopo da estratégia de busca para a realização do estudo

\begin{tabular}{ccccc} 
F23G5/27 & C10L1/02 & C11B1/10 & C12P7/64 & NúMERO DE PATENTES \\
X & X & X & & 8 \\
X & & $X$ & 0 \\
$X$ & $X$ & & 1 \\
& $X$ & $X$ & 189 \\
& $X$ & $X$ & 263 \\
$X$ & $X$ & & 326 \\
$X$ & $X$ & $X$ & 0 \\
$X$ & $X$ & $X$ & 0 \\
& $X$ & $X$ & 0 \\
\hline
\end{tabular}

Fonte: Elaborada pelos autores deste artigo (2020)

\section{Resultados e Discussão}

Entre as combinações abordadas na Tabela 2, a que melhor se enquadrou para o estudo aprofundado foi a união dos códigos C11B1/10 e C12P7/64, que apresenta 326 resultados.

As invenções contemplaram, principalmente, métodos e processos para obter compostos oleaginosos a partir de biomassa de microrganismos, incluindo as microalgas. Contudo, verificou-se com o estudo das patentes que elas reportavam propostas de métodos de obtenção de compostos oleaginosos diferentes do objetivo da pesquisa a ser realizada a partir dessa prospecção, o que ratifica a conveniência de mais estudos com esse tema. 
Foram pesquisadas tecnologias nas áreas de pirólise sem catalisador e usando catalisadores de nióbio, a partir de microrganismos, incluindo as microalgas, fração lipídica de biomassas contendo óleos vegetais, produção de biocombustíveis, englobando diesel verde.

A Figura 1 apresenta a quantidade de patentes depositadas por ano, com um recorte temporal entre os anos de 1976 e 1984, nos quais houve um total de dois depósitos, valor muito acima dos retratados nos demais anos.

Figura 1 - Quantidade de patentes depositadas por ano

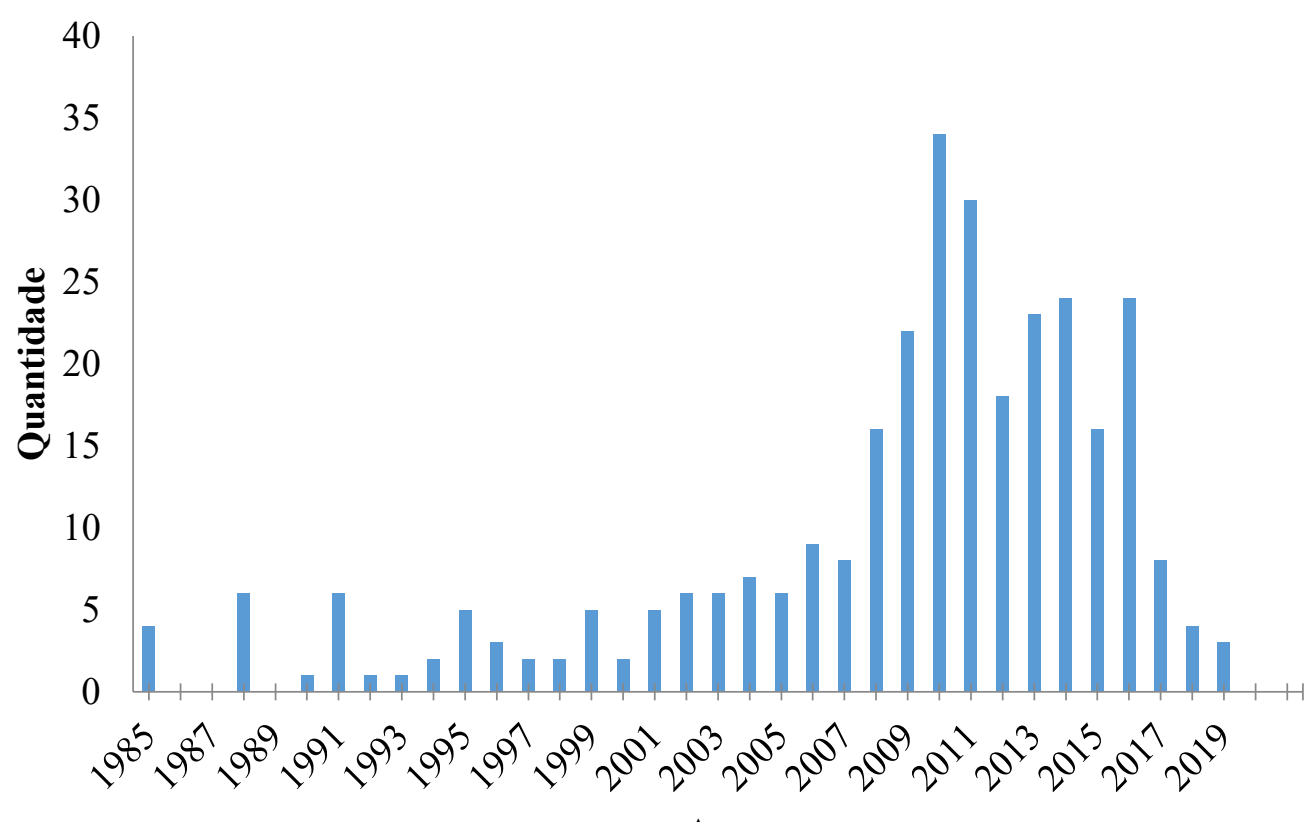

Ano

Fonte: Elaborada pelos autores deste artigo (2020)

Verifica-se que, entre os anos de 2008 e 2016, a tecnologia passou por uma fase de crescimento, o qual pode estar relacionado ao fato de que, nos Estados Unidos, a alta no preço do petróleo e os subsídios governamentais fizeram com que a produção de etanol a partir de milho crescesse de forma rápida (período 2006-2007). No entanto, a utilização de grande parte da produção de milho para o setor de combustíveis provocou choques com o setor alimentício, ao causar um aumento no preço desse grão não somente nos Estados Unidos, como também em diversos países. Por esse motivo, o subsídio para a produção de biocombustíveis, no geral, pode ter acarretado um crescimento rápido no depósito de patentes, devido à procura de novas matérias-primas e métodos para essa finalidade (BIODIESEL BR, 2007a). O número de patentes dobrou de 8 para 16 entre os anos de 2007 e 2008, chegando a 34 patentes depositadas no ano de 2010.

O ano de 2007 foi marcado por discussões da utilização da área de plantio para a produção de biocombustíveis, o que acarretaria problemas não somente na alimentação (alta nos preços dos grãos) como também de futura escassez de água. Segundo o Fundo das Nações Unidas para Agricultura e Alimentação, há uma grande probabilidade de que $60 \%$ da população mundial sofra com a escassez de água, dentro de 20 anos, devido, entre outros motivos, 
à produção de biocombustíveis. Tal fato pode ter acelerado ainda mais as pesquisas de fontes alternativas de biocombustíveis, o que pode justificar o grande número de patentes que usam fungos e microalgas como matérias-primas (BIODIESEL BR, 2007b). A partir de 2011 houve uma queda no número de depósitos de patentes com essa temática até o ano de 2019, que apresentou apenas três depósitos. Essa queda pode ter relação com uma crise financeira mundial, ocasionada em 2008, pelo banco de investimentos estadunidense Lehman Brothers. Essa crise se estendeu até 2009 e afetou diretamente a área de desenvolvimento de pesquisas e das usinas. Tais efeitos podem ter refletido nos depósitos por volta do ano de 2011 por causa do tempo de resposta, tanto para início da pesquisa quanto para depósito. Cabe aqui ressaltar que há, ainda, um período de 18 meses em que a patente deve ser mantida em sigilo.

A Figura 2 mostra a quantidade de patentes depositadas por país.

Figura 2 - Quantidade de patentes depositadas por país

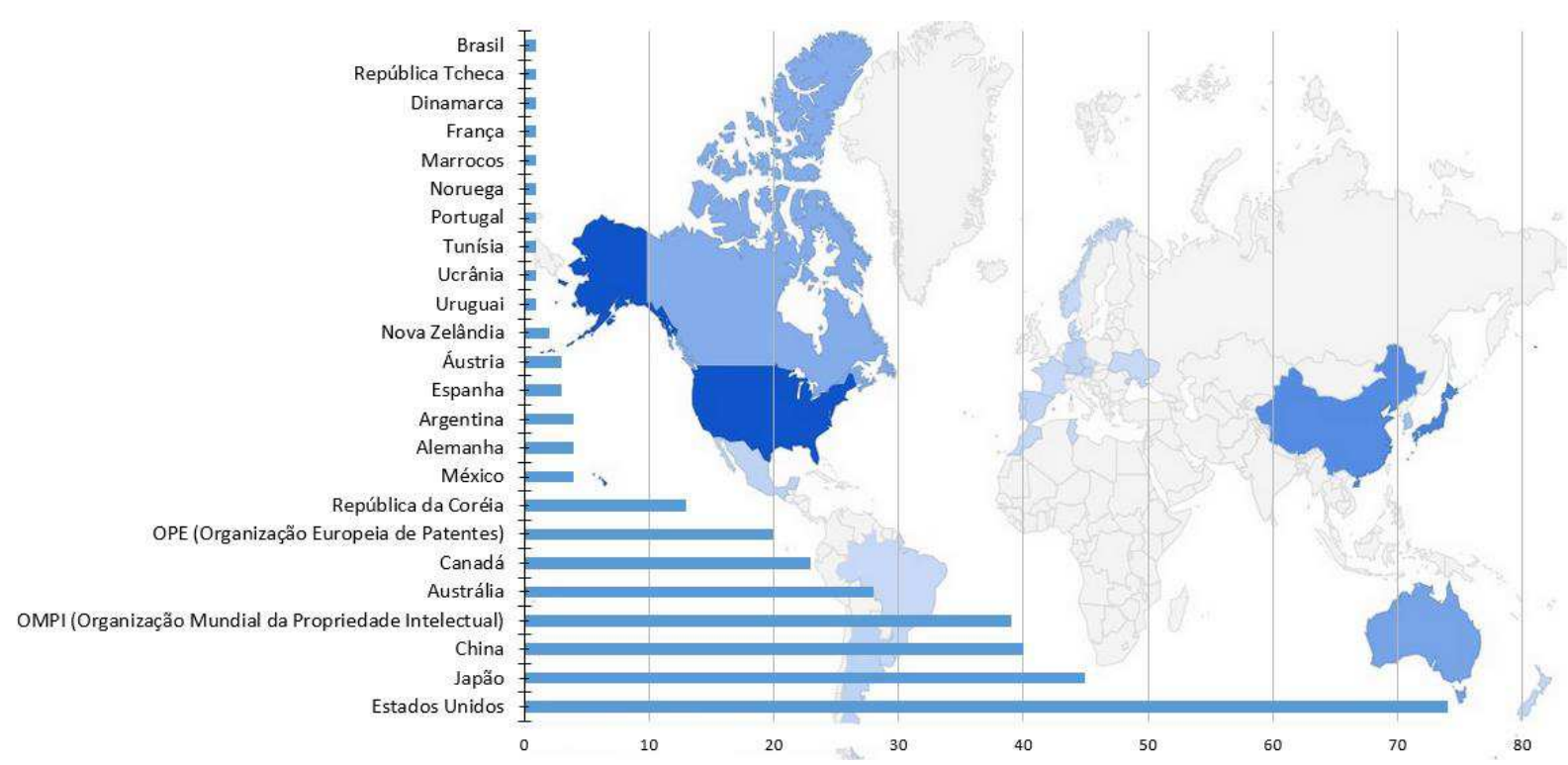

Fonte: Elaborada pelos autores deste artigo (2020)

Com relação à distribuição da tecnologia entre os países, a Figura 2 mostra que os Estados Unidos foram pioneiros, depositando 74 das 312 patentes, seguido pelo Japão com 45 depósitos e pela China com 40 depósitos. No Brasil, houve o depósito de apenas uma patente. Essa invenção refere-se ao processo de fabricação de álcoois superiores como subprodutos da produção de etanol (REDFORD, 2014).

A Figura 3 representa a porcentagem das patentes depositadas por empresas privadas, instituições governamentais e universidades. 
Figura 3 - Patentes depositadas por empresas

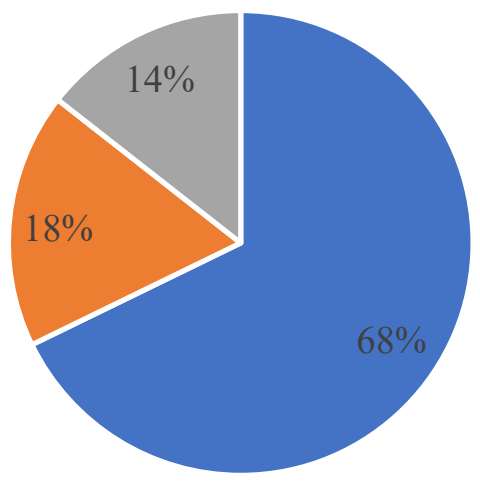

- Empresas privadas $\quad$ Governamentais $\quad$ Universidades

Fonte: Elaborada pelos autores deste artigo (2020)

Na Figura 3 observa-se que $68 \%$ das patentes foram depositadas por empresas, sendo a DSM IP Assets B.V. a que possui maior número de patentes, com 22 depósitos (CSIRO, 2020).

A DSM é uma multinacional que tem como propósito abordar os maiores desafios globais, atuando na área de nutrição, saúde e vida sustentável (DSM, 2020).

Já as instituições governamentais foram responsáveis por $18 \%$ das patentes depositadas, com a Commonwealth Scientific and Industrial Research Organisation (CSIRO) depositando 17 patentes. A CSIRO é a agência nacional de pesquisa australiana que busca solucionar desafios por meio da inovação, da ciência e da tecnologia.

As universidades contribuíram com $14 \%$ dos depósitos, com três patentes depositadas pela Universidade do Arizona, que se encontra entre as 50 melhores universidades dos Estados Unidos, estando na $41^{\circ}$ posição entre as instituições de pesquisa do país (THE UNIVERSITY OF ARIZONA, 2020).

A Figura 4 apresenta as matérias-primas que foram utilizadas nas patentes.

Figura 4 - Matérias-primas utilizadas nas patentes

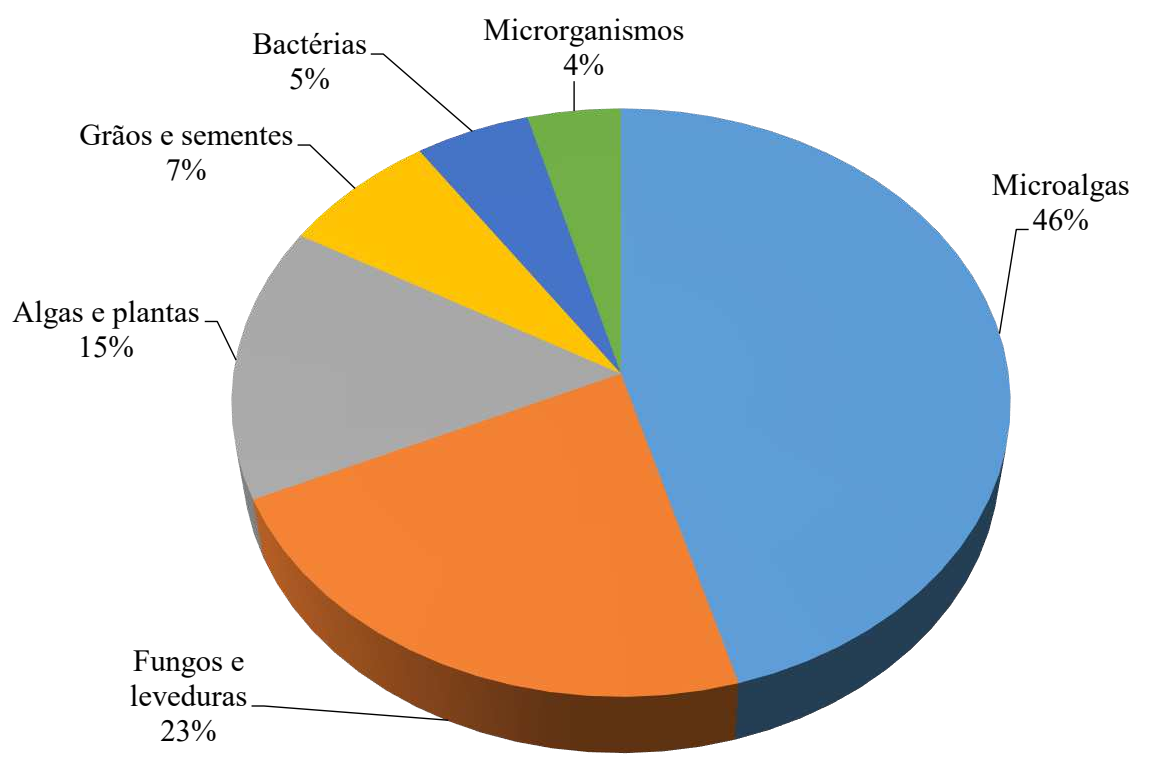

Fonte: Elaborada pelos autores deste artigo (2020) 
Verifica-se na Figura 4 que as microalgas foram estudadas em prioridade, seguidas por fungos e leveduras. Uma vez que os combustíveis à base de petróleo são responsáveis pela emissão de dióxido de carbono (CO), o qual é o maior contribuinte para o aumento do efeito estufa, a busca por combustíveis mais limpos é crescente e necessária. Diante disso, a ampliação de pesquisas e desenvolvimento de biocombustíveis mais evoluídos e renováveis torna-se imprescindível. Isso posto, ressalta-se que as microalgas têm sido estudadas como fonte de produção de biocombustíveis e estão entre os organismos fotossintéticos de crescimento muito rápido, além de possuírem a capacidade de se adaptar facilmente a várias condições climáticas (SUALI; SARBATLY, 2012). Além disso, as microalgas não seguem os esquemas típicos de cultivo, quando comparadas às culturas alimentares, e podem ser produzidas durante todo o ano (ZHANG, 2010).

Nesta pesquisa, os gêneros das espécies de microalgas mais utilizados foram Chlorella, Schizochytrium, Nannochloropsis e Thraustochytrium. Com relação aos gêneros dos fungos e leveduras, alguns dos mais citados foram, Mortierella, Saccharomyces, Thraustochytrid e Rhodotorula, entre as quais, Mortierella se destaca por apresentar maior número de citações (29) do que a microalga mais utilizada, Chlorella (26). A invenção de El Tahchy et al. (2011) refere-se a métodos de produção de hidrocarbonetos a partir de lipídios produzidos em plantas e em algas. Essa tecnologia é diferente da proposta desta pesquisa que objetiva um processo térmico e catalítico de produção de hidrocarbonetos a partir da fração lipídica de microalgas, na presença de catalisador de nióbio.

A Figura 5 apresenta os principais produtos químicos obtidos e mais citados nas patentes selecionadas.

Figura 5 - Principais Produtos Químicos

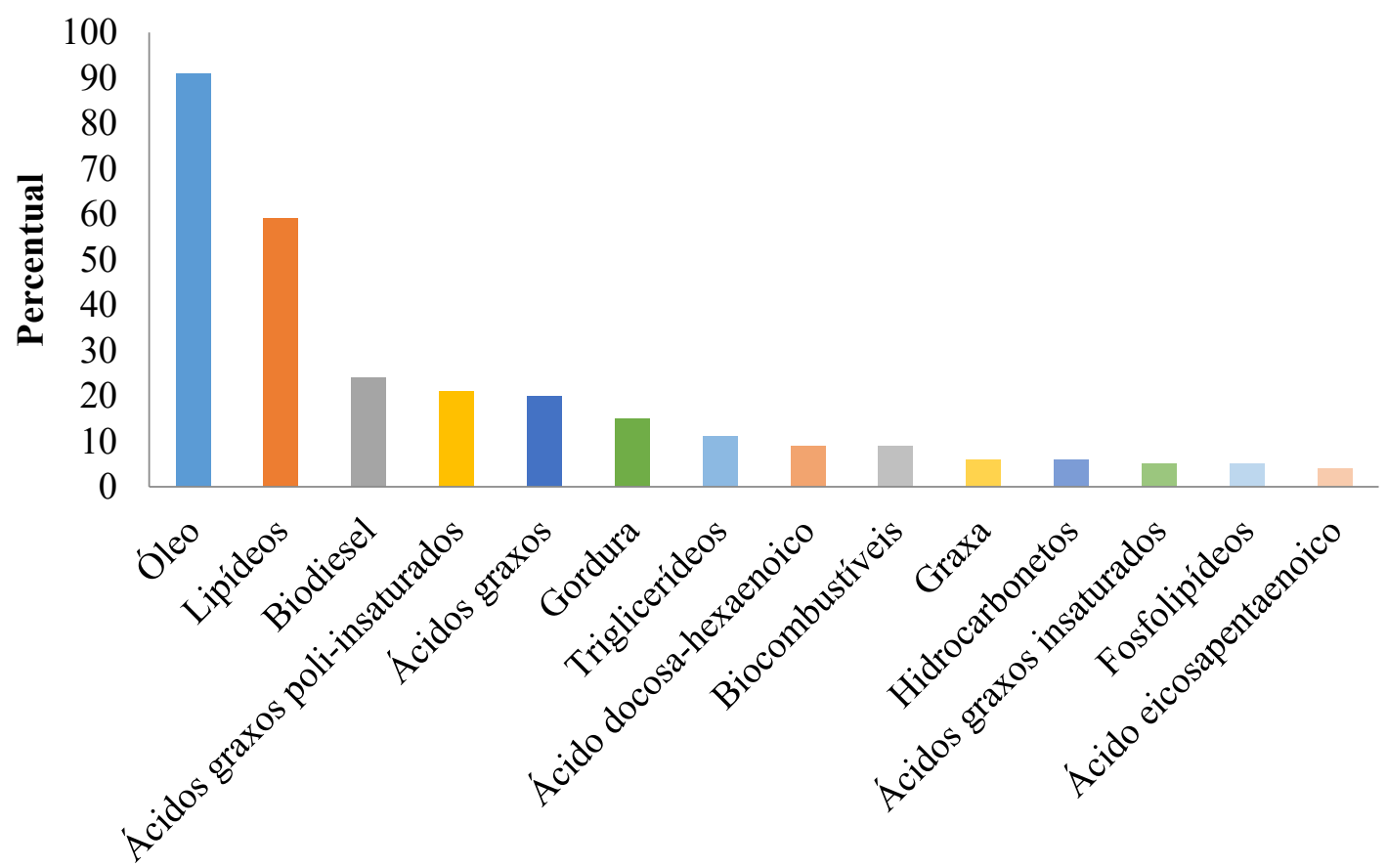

Fonte: Elaborada pelos autores deste artigo (2020)

A Figura 5 mostra que os principais produtos químicos procurados nas patentes foram óleo, lipídeos e biodiesel, com destaque também aos ácidos graxos, que foram citados de diversas 
formas, como ácidos graxos poli-insaturados, ácidos graxos insaturados, ácido docosaexaenoico $e$ ácido eicosapentaenoico. Entre os produtos químicos mais citados nas tecnologias usando os óleos vegetais e os lipídios extraídos das microalgas, se destaca o Biodiesel obtido por transesterificação e esterificação. Para converter os óleos em hidrocarbonetos, destacam-se os processos de desoxigenação e dehidroxilação, diferente da proposta do presente estudo que usa o processo de pirólise na conversão de lipídios em hidrocarbonetos na presença de catalisador de nióbio. A invenção de Hu e Sommerfeld (2008) fornece métodos para a produção de ácidos graxos ou hidrocarbonetos de cadeia média (C10-C14) a partir de algas. Após a extração, o óleo resultante é submetido a um processo de desoxigenação/dehidroxilação para converter o óleo em hidrocarbonetos.

Entre os produtos tecnológicos, algumas patentes podem ser comentadas. A Patente n. KR101826816 (B1) refere-se a um método para extrair óleo de um microrganismo. Esse método não requer etapa de secagem, evaporação e/ou uso de um solvente orgânico. A espécie de microalga utilizada foi a Hematococcus pluvialis, objetivando produção de biodiesel e diesel verde (KIM et al., 2016). A Patente n. JP201353299 (1A) descreve métodos e processos para obtenção de compostos oleaginosos a partir de biomassa de microrganismos, como as microalgas e cianobactérias. Os inventores avaliaram os compostos obtidos, como hidrocarbonetos e lipídios, e relatam que os produtos resultantes desses processos podem ser refinados, isolando-se em frações como combustível de aviação, diesel, gasolina, óleo combustível e óleo lubrificante (SOARES, 2014). A invenção de Redshaw (2014) refere-se a complexos formados pela combinação de um metal $(\mathrm{M})$ e de vários ligantes $(\mathrm{L})$. Os metais $(\mathrm{M})$ incluem nióbio e tântalo. Os complexos servem para catalisar a polimerização de hidrocarbonetos. O processo compreende misturar o complexo organometálico ou uma combinação dos complexos com um cocatalisador e um ou mais monômeros (REDSHAW, 2014).

Em trabalhos preliminares, Dourado et al. (2019) estudaram o catalisador $\mathrm{NbO}$ e observaram que os produtos gerados na pirólise da microalga Nannochloropsis oculata confirmam a desoxigenação dos lipídios, transformando-os em hidrocarbonetos verdes na faixa do diesel. Esse e outros estudos relacionados estão em andamento.

\section{Considerações Finais}

O uso das microalgas para a produção de biocombustíveis tem levado a um respeitoso número de depósitos visando a usar os compostos oleosos e os carboidratos sintetizados por esses microrganismos. Entretanto, o aproveitamento desses microrganismos nos processos de pirólise na ausência ou na presença de catalisadores para a produção de biocombustíveis permanece escasso.

O país pioneiro com maior número de patentes, depositando 74 das 312 patentes encontradas, foi os Estados Unidos, seguido por Japão com 45 depósitos e China com 40 depósitos.

Os processos mais citados nessas patentes referem-se a métodos para extrair fração lipídica, enquanto os produtos mais citados foram óleo, lipídeos e biodiesel.

A grande maioria das patentes depositadas abrange os métodos usados para extração do bio-óleo, conversão de óleos vegetais em hidrocarbonetos via processos de desoxigenação e de desidroxilação. 
Sendo assim, com base nesta prospecção, os estudos realizados no Laboratório de Bioenergia e Catálise (LABEC) da Universidade Federal da Bahia (UFBA), aproveitando processos de pirólise na transformação de microalgas e dos lipídios extraídos destas em hidrocarbonetos na presença de um catalisador, aparecem como uma via alternativa de produção de biocombustíveis mais limpos.

\section{Referências}

ALEXANDER, D. G. et al. Method for Extracting Ingredient from Natural Products. DE2424612 (A1), 1973.

ALMEIDA, H. N. et al. Characterization and Pyrolysis of Chlorella Vulgaris and Arthrospira Platensis: Potential of Bio-Oil and Chemical Production by Py-GC/MS Analysis. National Library of Medicine, [s.l.], v. 24, n. 16, p. 14.142-14.150, 2017.

BABICH, I. V. et al. Catalytic pyrolysis of microalgae to high-quality liquid bio-fuels. Biomass and Bioenergy, [s.l.], v. 35, p. 3.199-3.207, 2011.

BATISTA, L. M. B. et al. Synthesis, characterization and evaluation of niobium catalysts in the flash pyrolysis of glycerol. Solid State Sciences, [s.l.], v. 97, p. 105977, 2019.

BIODIESEL BR. [2007a]. Disponível em: https://www.biodieselbr.com/destaques/2007/bolha-dosbiocombustiveis. Acesso em: 20 nov. 2020.

BIODIESEL BR. [2007b]. Disponível em https://www.biodieselbr.com/biodiesel/retrospectiva//2007alimentos-x-biocombustiveis. Acesso em: Acesso em: 20 nov. 2020.

BIODIESEL no Mundo. Publicado em 2 jan. 2014. Disponível em: https://www.biodieselbr.com/ biodiesel/mundo/biodiesel-no-mundo. Acesso em: 28 abr. 2020.

BRASIL. Ministério de Minas e Energia. Importância do nióbio para o Brasil e para o mundo. [2020a]. Disponível em: http://www.mme.gov.br/web/guest/todas-as-noticias/-/asset_publisher/ $\mathrm{pdAS9IcdBICN/content/seminario-no-mme-mostra-importancia-do-niobio-para-o-brasil-e-para-o-}$ mundo. Acesso em: 18 abr. 2020.

BRASIL. Ministério de Minas e Energia. [2020b]. Disponível em: www.mme.gov.br web/guest/buscaportal. Acesso em: 4 mar. 2020.

BRANDÃO, R. F. et al. Synthesis, characterization and use of $\mathrm{NbO}$ based catalysts in producing biofuels by transesterification, esterification and pyrolysis. Journal of the Brazilian Chemical Society, [s.l.], v. 20, p. 954-966, 2009.

BRIDGWATER, A. V. Review of fast pyrolysis of biomass and product upgrading. Biomass and Bioenergy, [s.l.], v. 38, p. 68-94, 2012.

DOS SANTOS, Camila C. A. Avaliação do efeito das condições de cultivo na produção de biomassa e lipídeos da microalga Halamphora Coffeaeformis. 2019. 79p. Dissertação (Mestrado) - Escola Politécnica da Universidade Federal da Bahia, Salvador, 2019.

CHAGAS, B. M. E. et al. Catalytic pyrolysis-GC/MS of Spirulina: Evaluation of a highly proteinaceous biomass source for production of fuels and chemicals. Fuel, [s.l.], v. 179, p. 124-134, 2016. 
EXAME. Crise Financeira de 2008 arrasava a economia mundial. Publicado em 14 set. 2018. Disponível em: https://exame.abril.com.br/economia/ha-10-anos-crise-financeira-de-2008-arrasavaa-economia-mundial/. Acesso em: 28 abr. 2020.

CSIRO - COMMONWEALTH SCIENTIFIC AND INDUSTRIAL RESEARCH ORGANISATION. [2020]. Disponível em: https://www.csiro.au/ Acesso em: 2 jun. 2020.

DOURADO, M. S. et al. Pirólise da microalga Nannochloropsis oculata para a produção de diesel verde. In: $7^{\circ}$ CONGRESSO DA REDE BRASILEIRA DE TECNOLOGIA E INOVAÇÃO DE BIODIESEL. Florianópolis, Santa Catarina, 2019. Anais [...]. Florianópolis, SC, 2019.

DSM. Sustainability. [2020]. Disponível em: https://www.dsm.com/corporate/home.html. Acesso em: 2 jun. 2020.

DU, Z. et al. Microwave-assisted pyrolysis of microalgae for biofuel production. Bioresource

Technology, [s.l.], v. 102, n. 7, p. 4.890-4.896, 2011.

EL TAHCHY, A. et al. Processes for Producing Hydrocarbon Products. US2014256006 (A1), 2011.

ELKASABI, Y. et al. Hydrocarbons from Spirulina Pyrolysis Bio-oil Using One-Step Hydrotreating and Aqueous Extraction of Heteroatom Compounds. ACS Publications, [s.l.], v. 30, n. 6, p. 4.925-4.932, 2016.

FORT JEAN, J. Method for Obtaining Fatty Acids. DE2756977 (A1), 1976.

HU, Q.; SOMMERFELD, M. Algal Medium Chain Length Fatty Acids and Hydrocarbons. CA2663808A1, 2008.

KIM, D. et al. Efficient Recovery of Oil from Oleaginous Microorganisms. KR101826816 (B1), 2016.

LOPES, O. F. et al. Óxidos de nióbio: Uma visão sobre a síntese do $\mathrm{Nb2O5e} \mathrm{sua} \mathrm{aplicação} \mathrm{em}$ fotocatálise heterogênea. Química Nova, [s.l.], v. 38, n. 1, p. 106-117, 2015.

MERCER, P.; ARMENTA, R. E. Developments in oil extraction from microalgae. European Journal of Lipid Science and Technology, [s.l.], v. 113, n. 5, p. 539-547, 2011.

PIMENTEL, M. B.; AQUINO, M. A.; LOBATO, A. K. C. L. Avaliação do Uso da Biomassa Úmida na Produção de Biodiesel a partir de Microalgas. Cadernos de Prospecção, Salvador, v. 11, n. 5, p. 1.420-1.437, 2018.

REDFORD, S. G. Composições Oleosas e Métodos de Produção. BR112014020547 (A2), 2014.

REDSHAW, C. Niob and tantal complexes as catalysts for olefin polymerization. WO2014135824 (A1), 2014.

REGUERA, F. M. et al. The use of niobium based catalysts for liquid fuel production. Materials Research, [s.l.], v. 7, n. 2, p. 343-348, 2004.

SANTOS, C. C. A. et al. Prospecção Tecnológica de Patentes Sobre Cultivos de Microalgas Visando a Produção de Biodiesel. Cadernos de Prospecção, Salvador, v. 11, n. 4, p. 1.057-1.068. 2018.

SIMÃO, B. L. et al. Pyrolysis of Spirulina maxima: Kinetic modelling and selectivity for aromatic hydrocarbons. Algal Research, [s.l.], v. 32, p. 221-232, 2018. 
SOARES, M. C. Q. Method for Recovery of Lipids or Hydrocarbons. JP201751206 (2A), 2014.

SUALI, E.; SARBATLY, R. Conversion of microalgae to biofuel. Renewable and Sustainable Energy Reviews, [s.l.], v. 16, n. 6, p. 4.316-4.342, 2012.

TANABE, K. Catalytic application of niobium compounds. Catalysis Today, [s.l.], v. 78, n. 1, p. 6577, 2003.

THE UNIVERSITY OF ARIZONA. [2020]. Disponível em https://global.arizona.edu/admissions/ portugu\%C3\%AAs. Acesso em: 2 jun. 2020.

XIA, Q. et al. Cooperative catalysis for the direct hydrodeoxygenation of vegetable oils into dieselrange alkanes over $\mathrm{Pd} / \mathrm{NbOPO}$. Chemical Communications, [s.l.], v. 52, p. 5.160-5.163, 2016.

YI, Y. et al. $\mathrm{Pd} / \mathrm{NbO} / \mathrm{SiO}$. Catalyst for the Direct Hydrodeoxygenation of Biomass $\square$ Related Compounds to Liquid Alkanes under Mild.Conditions. Chem. Sus. Chem, [s.l.], v. 8, p. 1.7611.767, 2015.

ZAINAN, N. H. et al. Quality of bio-oil from catalytic pyrolysis of microalgae Chlorella vulgaris. Fuel, [s.l.], v. 223, p. 12-19, 2018.

ZHANG, X. W.; GONG, X. D.; CHEN, F. Kinetic models for astaxanthin production by high cell density mixotrophic culture of the microalga Haematococcus pluvialis. Journal of Industrial

Microbiology \& Biotechnology, [s.l.], v. 23, n. 1, p. 691-696, 1999

\section{Sobre os Autores}

\section{Mailena Silva Dourado}

E-mail: mailenadsilva@gmail.com

ORCID: https://orcid.org/0000-0001-7542-0294

Mestre em Engenharia Industrial pelo Programa de Engenharia Industrial da UFBA em 2015.

Endereço profissional: Escola Politécnica, Rua Prof. Aristídes Novis, n. 2, Federação, Salvador, BA. CEP: 40210-630.

\section{Beatrice Araújo Mascarenhas}

E-mail: beatricemascarenhas@gmail.com ORCID: https://orcid.org/0000-0001-9580-405X

Graduanda em Engenharia Química na Escola politécnica da Universidade Federal da Bahia (cursando).

Endereço profissional: Escola Politécnica, Rua Prof. Aristídes Novis, n. 2, Federação, Salvador, BA. CEP: 40210-630.

\section{Odete Gonçalves}

E-mail: odegoncalves7@gmail.com

ORCID: https://orcid.org/0000-0002-2428-9000

Doutora em Biotecnologia Industrial pela Renorbio UFBA em 2018.

Endereço profissional: Avenida Barão de Geremoabo, Instituto de Química da UFBA, Salvador, BA. CEP: 40170115. 


\section{Roger Thomas Fréty}

E-mail: ro_fre@hotmail.fr ORCID: http://orcid.org/0000-0002-4532-2105

PhD em Catálise pela Universite de Paris 7, Denis Diderot, em 1969.

Endereço profissional: Avenida Barão de Geremoabo, Instituto de Química da UFBA, Salvador, BA. CEP: 40170115.

\section{Emerson Andrade Sales}

E-mail: andradesales.emerson@gmail.com

ORCID: http://orcid.org/0000-0002-9607-7285

Pós-doutor em Biorrefinaria de Microalgas em 2018. Department of Pollution Control and Environmental Engineering, na Índia.

Endereço profissional: Escola Politécnica, Rua Prof. Aristídes Novis, n. 2, Federação, Salvador, BA. CEP: 40210-630. 